\title{
The Role of the PBL Tutor Within Blended Academic Development
}

Roisin Donnelly

Technological University Dublin, roisin.donnelly@tudublin.ie

Follow this and additional works at: https://arrow.tudublin.ie/ltcart

Part of the Educational Assessment, Evaluation, and Research Commons

\section{Recommended Citation}

Donnelly, R.: The Role of the PBL Tutor Within Blended Academic Development. Innovations in Education and Traning International, 2011.

This Article is brought to you for free and open access by

the Learning Teaching \& Assessment at ARROW@TU

Dublin. It has been accepted for inclusion in Articles by an authorized administrator of ARROW@TU Dublin. For more information, please contact arrow.admin@tudublin.ie, aisling.coyne@tudublin.ie, gerard.connolly@tudublin.ie. 


\section{The Role of the PBL Tutor within Blended Academic Development}

The central idea of this study is using blended problem-based learning (PBL) in an academic development context with key roles emphasised: academic staff in the role of students and the academic developer as the tutor. The context is a module entitled 'Designing eLearning' on a postgraduate programme for academic staff in Ireland. It is acknowledged that an e-learning literature exists that calls for more effective use of technology. Part of that exploration of e-learning value requires a refocusing on pedagogy. Increasingly $\mathrm{PBL}$ is one of the pedagogies associated with the learning technologies available to educators today. Data was collected from face-to-face PBL tutorials, transcripts of online discussion boards, focus groups and student reflective papers generated over two years and involving all the participants (17) who chose to undertake the module as part of their professional development. The findings highlight key issues for the complex role of the PBL tutor in further understanding the blending of traditional PBL with the technologies afforded by e-learning.

Keywords: academic development; blended delivery; e-learning; facilitation; problem-based learning; technology 


\section{Introduction}

The literatures available on blended learning and problem-based learning (PBL) in higher education has increased substantially in recent years, with a growth in studies available on blending various technologies with PBL to varying degrees of success (Taradi et al., 2005; Rossiter, 2008; Beaumont et al., 2008). However, it is worthy to note that this has mainly been documented from the perspective of undergraduate education and specific to using PBL with undergraduate students. Depending on its situated context, it is recognised that PBL is not a new form of education but increasingly, teachers and academic developers will need to be familiar with its implications. The essence of this paper is the interplay of new technologies and pedagogies; however the study is contextualized in the field of academic development with a view to understanding academic staffs' experiences as students in a technology-based PBL environment, and specifically, the role of the tutor therein. Although the tutorial is the central and key learning encounter in PBL curricula and the integration of technology has increased in practice in recent years, within a blend of face-to-face and virtual PBL tutorials Savin-Baden (2006) has argued is a notion of unrealized complexity that needs to be more fully understood. This paper aims to address this by providing research-based information about the realities of delivering a programme for academic staff using a blend of PBL and technology.

In this global time of uncertainty for higher education (HE), challenges remain and indeed have expanded for academic developers in how they can best support the academic staff in their institutions, particularly in the area of online pedagogy (Fox \& Herrmann, 2000). Over the past decade, e-learning has been previously implemented in academic development programmes (Shephard, 2004; Vogel, 2009). There have been some relevant studies citing tangible benefits of innovation and change and useful resources produced for academic developers to draw upon in their role (for example JISC podcasts, 2009) and in 
specific teaching contexts such as large class teaching (Gunn \& Harper, 2006). However others have cautioned about being influenced by the e-learning tsunami of hype that had been generated (Driscoll, 2008). As a result it is important to objectively consider what influences teaching staff engagement and participation in online environments. It is suggested here that the need to encourage engagement amongst academic staff with regard to their e-learning and pedagogical professional development opportunities has never been greater. In an Irish higher education context, trends have been noted that academic staff development is focusing on technology among other key factors such as accreditation (MacLaren, 2005) and the recent Hunt Report (2011) which outlines a 20 year strategy for higher education in Ireland reiterates the need to continue that development. Through a critical examination of interactions within the blended PBL tutorial, this study aims to provide insights and give consideration to practical implications for the tutor in blending pedagogy and technology in PBL.

At this juncture, it is useful to clarify the nature of PBL in general and then move on to explicitly address blended PBL in the subsequent section. However, as Newman (2004) argues it is not always clear what exactly is being done in the name of PBL, and its wide dissemination has, in effect, generated many variations (Barrows, 1987). It has been defined as an educational strategy that involves the presentation of significant, complex and "realworld" problems to learners that are structured in such a way that there is not one specific correct answer or predetermined outcome (Barrows, 1987). Savin-Baden (2003) suggested that the often unarticulated aim of teachers who use PBL approaches is to develop in their students 'criticality' - emotional, intellectual and practical independence.

The paper proceeds with an outline of the academic development context of the study, followed by a discussion of pertinent literature on blended PBL and the tutor role; thereafter 
is the detailing of the qualitative research study conducted with academic staff in a face-toface and virtual PBL tutorial setting.

\section{Context}

Like PBL, there are also many definitions currently for blended learning and the definitional debates explore different notions of face-to-face and online learning opportunities; however, they seem to converge around the idea of synthesizing e-learning with the more traditional forms of teaching and learning, drawing together the 'e' with the classroom, the laboratory, the seminar and the tutorial setting, utilising the strengths of all (Osguthorpe \& Graham, 2003).

In Ireland, as elsewhere, the use of online technologies has become an increasingly important challenge in academic staff development, and on the surface, e-learning has been moderately successful in the teaching and learning environment. The focus of the research reported here is a module on a postgraduate programme entitled 'Designing e-learning' for academic staff. The postgraduate qualification in this context is awarded typically after a bachelor's degree and indicates graduate-level studies or advanced studies in an already familiar field to all participants. The module at the heart of this study is one of a number of ten week modules. The current and emerging HE environment in the Institute where the study was located, as elsewhere, is seeking solutions to problems of changing paradigms of learning and the influx of learning technologies.

The rationale for using PBL on this programme was to provide a strategy for the participants which was learner-centred, motivating, relevant to their academic practice, and adaptable to their needs as adult learners. A further ambition was to promote collaboration across a number of disciplines across the institution and between institutions. The content of the module was how to design and tutor e-learning within a PBL approach. The learning outcomes for the participants thus involved a mix of practice-based e-learning competencies 
and skill-based PBL. While it was originally influenced by the Barrows (1987) tutorial process for PBL, the approach favoured on this programme can be summarised as including stages of problem identification, deconstruction, seeking and using knowledge and experience, understanding, thinking, choosing a strategy, acting and then critically evaluating and reflecting on the action.

In the module, blended PBL involved the participants working collaboratively in small groups, with their discussions and work on a real life scenario spanning both the PBL tutorial and the asynchronous (discussion boards, wiki) and synchronous (chatroom and whiteboard) features of the Blackboard learning environment. Video conferencing and social software such as blogs were also used. The blended PBL approach was varied and flexible and introduced questions for the academic staff about the dual role of what it means to be a problem-based learner and tutor in both a classroom and online setting.

This study presents the opportunity to work with eager members of the teaching community in offering a different approach to their academic development. As all participants on the module were self-selecting and choose to pursue this professional development opportunity themselves, arguably this was a situated reality in that participants were motivated and keen to explore the blended PBL approach offered through the module.

\section{Blended PBL in the Context of Academic Development}

A review of practical case studies, conceptual work and research-based inquiry for the use of blended PBL in academic staff development reveals considerable variations in context, all which were of background interest to the study. In the past several years there have been studies conducted into the effectiveness of PBL in a higher education virtual environment, from a number of differing staff development contexts; for example in Ireland (Jennings, 2006)), and in Finland (Portimojärvi \& Vuoskoski, 2006), and also in a fully online context within PBL postgraduate programmes in Engineering for academic staff, such as a those 
offered at the University of Aalberg (Kolmos et al., 2008); there has also been work conducted into the traditional PBL tutorial in a staff development context (Barrett, 2007).

Kolmos (2002) has reported that in spite of an extensive staff development programme to introduce teachers to a new PBL model, the change in the nature of teaching caused problems with retention and curriculum. Academic developers were urged to be aware of the need to facilitate the change at individual, culture and organisational levels, which is a comprehensive challenge in itself.

There has been a multitude of studies conducted on the role of the tutor in e-learning. As some of the more recognized guides for tutors, Brescia's (2002) telementoring taxonomy emphasized coaching through participation and Levin (1995) built his taxonomy on structure, process, mediation and community building. However again, these are situated within research on undergraduate students.

The role of the tutor has been central to investigations of blended learning. However, before the 'e' came to learning and tutoring, Fosnot (1996) eloquently notes that one of the tutor's roles is to ask questions at the cutting edge of the learner's understanding, thus supporting the structure of the participants' thinking while still pushing it ahead. Finkle \& Torp (1995) described the tutor's role as 'cognitive coaching', something quite different from the more typical 'content coaching'. Taking this further, Northedge (2003) in exploring the face-to-face tutor's role, associates them as subject expert having three key roles to play in enabling learning: lending the capacity to participate in meaning; designing well planned excursions into unfamiliar discursive terrain; and coaching learners in speaking the academic discourse. In one of the earliest blended studies, Kulp (1999) advocates some similarities between face-to-face and online tutor skills: amongst others already mentioned, he suggests that expertise in their subject matter; expertise in pedagogical issues; and technical skills are all prerequisites. 


\section{Research Study}

The research objective of the study was to establish, in a PBL tutorial setting within an academic development context, the factors that govern the success of problem-based learning in a blend of face-to-face and online environments.

It is recognised that narrative inquiry, phenomenology and action research are just three of the methodologies that have been used by other PBL studies previously, and interaction analysis has been used to understand the goals and strategies of an expert facilitator in support of collaborative learning (Hmelo-Silver \& Barrows, 2006). A case study methodology was appropriate for this study as it is an empirical investigation of a particular contemporary phenomenon within its real life, natural context using multiple sources of evidence (Robson, 1993). Case study research would allow attention to minute levels of detail in the specific context of this module. The underlying epistemology is constructivistinterpretive, since it was the perceptions of all participants that were explored and their various possible interpretations and meanings. Lycke et al. (2002) and Dolmans (2002) both recommend the use of qualitative studies to obtain a more detailed insight into the conceptions that underlie activities in PBL groups. Influenced by this, the current study uses a range of qualitative data collection methods in order to analyse participants' experience of a blended PBL approach to academic development in higher education.

Studying the natural setting can help document how learners in real PBL situations and contexts helps us understand the complexity of learning and teaching in blended PBL environments and offers insights that can be useful in developing our practice as tutors. To achieve this, a research approach had to be adopted that predominantly seeks to 'tell their story'. All 17 participants ( 8 males and 9 females) on the module participated in the study; they were academic staff members drawn from a number of higher education institutions, and were all either lecturers or educational support staff. The nature of these academic staff's 
varied work responsibilities today is complex, with demands on their time (ranging from lesson preparation, student support and research, to staff meetings, and curriculum development) pulling them in many directions. Fifteen different subject disciplines were represented as follows in three PBL groups:

- Group 1 (psychology, social science, culinary arts, information literacy, adult literacy);

- Group 2 (biology, apprentice plumbing, apprentice joinery, apprentice metalwork, adult literacy);

- Group 3 (architecture, marketing, culinary arts, refrigeration, printing, fine art, chemistry).

It is noted that a number of the participants hail from what is referred to as vocational subjects, entitled here 'apprenticeship' education. There is room for further work in combining PBL, web-based distributed education, and a problem-solving environment to create effective learning environments in a variety of disciplines and modes.

The research methods employed to collect face-to-face and online observational data from three PBL groups in this two year study were participant observation, online discussion transcripts, open-ended focus group interview and self-reflective papers to capture the participant's own thoughts and experiences of the blended PBL approach. Each method was chosen for the opportunity it could offer to explore participant interactions with each other and with the tutor, which were central to this study.

\section{Data Analysis}

The textual evidence from the interview transcripts and participant reflective papers were analysed using thematic analysis to find patterns and proposing interpretations of the patterns together with accounts of the meanings and ideological significance of these patterns. The use of direct quotes (with pseudonyms) is used in this findings section to provide evidence of 
both the shared enthusiasm for the blended PBL tutoring process and also some real concerns voiced by the academic staff participants.

\section{Findings}

The main finding of the study was the identification of distinct roles for the PBL tutor within a blended learning tutorial experience. The first was the sense of tutor positiveness that needs to be present at all times:

The tutor should be an inspiration with an infectious attitude; dedication and commitment is key, as well as being helpful and cheerful; knowing when to step in and when to just observe is useful. (Sorcha, Focus Group interview 2)

Participants also expressed that blended PBL requires the tutor to know when to 'shift gears' and add new tasks or resources and alternatively when to let the learners explore their own interests:

Bringing us back on track and sorting any problems without delay was so useful.

The tutor needs to be patient, hard-working, enthusiastic and should have high expectations of the groups, knowing when to push us on and upwards and when to leave us to our own devices! (Loirin, Focus Group interview 1)

A sense of the importance of tutor authority and presence was also prevalent. When working on a problem where the tutor does not know the answer, a great deal of authority can be gained not by pushing a better solution forward, but by using arguments within the learners' horizon that show why some of their suggestions are inappropriate and unlikely to succeed:

I felt it important that we knew the tutor was keeping an eye on our online discussions but in a benign manner; being positive, interested and encouraging and providing fantastic individual feedback, especially around reflection was key; also knowing that the tutor was being honest and gracious when making a mistake was very important to me. (Aine, Focus Group interview 2) 
I think that content is very important as well here; I knew you were there but I didn't feel you weren't imposing yourself upon us. So in our case, we had an expert at all times but it wasn't like an authoritarian figure either; we were able to go our own way but you were there to guide us and I can't imagine how it work with a PBL facilitator who was not au fait with the area of e-learning. (Niamh, Focus Group Interview 1)

In the online environment the PBL tutor needs to be didactic and specific to overcome any ambiguity or misunderstanding:

The tutor should be an inspiration with an infectious attitude; dedication and commitment is key, as well as being helpful and cheerful; knowing when to step in with coherent directions and when to just observe is so useful. (Loirin, Reflective Paper 2)

What struck me most was the fact that you always had an online presence; I felt that you were always there, even if you weren't. Not that you were watching all the time but that you came in with suggestions and references to further aspects of the topic; I felt that that was very important, guiding us. I didn't feel that you were butting in when you shouldn't have. (Caitlin, Focus Group Interview 2)

Yes indeed, when our discussions on the problem continued online, I forgot about you, when you stepped back from it all; and then Niamh posted a message to us all, and asked the tutor a question as part of it, and I thought, why is she asking the tutor here, she mightn't see this, why not send her an email? And you 
responded straight away, and I had forgotten that you were there.

(Sorcha, Focus Group Interview 2)

\section{Discussion of the Roles of the PBL Tutor and Recommendations}

Kamin et al. (2006) had previously argued that there was little research describing the skills needed to facilitate PBL online. Within any PBL context, it can be argued that the tutor needs to create and support an organised and collaborative learning environment. Within a blended environment, the risk is great that switching between classroom and e-learning within a module could lead to chaos and a disorganized learning process. In this current study, the tutor responses of giving direct answers, explaining and elaborating and giving feedback, mirror categories labelled by other researchers in non-PBL settings as 'direct teaching' and 'questioning' (Berge, 1995), 'cognitive exchanges' (Henri, 1992) or 'pedagogical' roles (Teles, 2001). Henri (1992) also used the term 'social' to describe statements unrelated to the formal content of a message, such as greetings and expressions of feelings.

Blended PBL makes great demands on the tutor, but Smith et al. (2005) have noted that the literature has provided little guidance on which specific tutor behaviours scaffold collaborative practices. Key to the success of the tutor in blended PBL is the skill required to pose questions to learners and the recognition that they must surrender what Mayo \& Donnelly (1995) have called 'the seat of the authority'. However learners have a keen eye for fake enthusiasm for a topic and tutors who feel that their authority lies in knowing all the answers have little chance of awakening genuine curiosity in their discipline.

Both tutors and learners see online discussion as a means to encourage critical thinking and contribute to their understanding. Some participants viewed the extent of tutor skills required in blended PBL as follows: 
I have had direct experience of facilitation tasks to be undertaken by the tutor and I will be putting them all into practice: leading introductory, community-building activities; prompting us intellectually; providing virtual "hand holding" to the digitally challenged; acknowledging the diversity of participants' backgrounds and interests; infusing personality with tone, graphics, and humour; maintaining a nurturing pace of responding; modelling how to critically evaluate, reflect and give prompt feedback; keeping up with the pace set; organizing posts and discussion threads; clarifying and directing; balancing private email and public discussion. (Declan, Reflective Paper 15)

While the above findings have been discussed in relation to the general PBL tutor literature, specifically within the academic development context, both Blye et al. (2005) and Morris (2005) discuss implications for faculty development in teaching and learning. Based on the findings of this current study, the role of the PBL tutor was to scaffold learning but was multi-faceted and complex. It was important to have a modus operandi in place to guide the participants in how to utilise information, giving advice directions and clarification. Intellectually this guidance needed to direct participants in what to consider, by providing hints and examples and urging them to reflect on their learning. A metacognitive stream needed to flow to guide participants in how to think in considering the PBL problem by suggesting to plan ahead, modelling cognitive strategies such as the acquisition of subject knowledge, encouraging critical appraisal of information and stimulating critical analysis of resources. Inherent in the role is the assessing of individual performances within the group and provision of frequent feedback but not at the expense of facilitation and development of good interpersonal relationships in the group.

All this can be a satisfying, energizing experience for the academic developer as tutor, yet tiring and difficult at times. Being unprepared for emotional intensity and participant 
resistance to change can lead to tutor frustration and strain. The process of blended PBL requires emotional investment, which is both pleasurable and painful as it promotes a sense of liberation and empowerment, yet also uncertainty. The climate of the blended PBL tutorial raises issues for consideration as the tutor role requires a transition from f2 $\mathrm{f}$ to online. Alongside the deliberate actions that the tutor undertook to support the learners in the PBL groups in both environs, there were what can almost be called automatic or personality traits that came to the fore - such as the use of humour, tone of language, a personal investment in their learning and a degree of emotion. There appeared a subliminal role for the tutor on this module, involving the use of a non-threatening, benign tone, humour, positive body language (in the face-to-face tutorials), a harnessing of emotions and a personal investment in the participants' learning. Regarding the tutor's subliminal role, Schön (1991, p54) has said that "there are actions, recognitions and judgments which we know how to carry out spontaneously; we do not have to think about them prior to or during their performance."

This tutor personalisation engenders trust and openness in the sometimes impersonal realm of online instruction. There is need for more investigation into the emotional impact of the transition from online to face-to-face PBL tutoring; while the functional element of PBL tutoring appears well explained in the literature, there appears little empirical research into this aspect. It is heartening that individual tutors can, it turns out, make a difference to the learning for academic staff engaged in professional development programmes such as this; so it is important to remind ourselves as educators that insights are needed into the support of staff as they prepare for and undertake the tutoring role for themselves.

Savin-Baden (2006) has indicated that there is still little understanding of what goes on in the minds of tutors and learners engaged in online PBL and that concerns about what and how students learn in groups is an area that has still not been particularly well resolved in online or face-to-face PBL contexts. She suggested that online PBL requires more of a silent 
presence by the tutor, along with appropriate hinting and prompting, rather than some of the direction and intervention that seems to be evident in much e-moderating. This view concurs with the research of Park et al. (2007) who, although in an undergraduate curriculum, explored the importance of the PBL tutor's expertise and experience on student performance.

\section{Conclusion}

The study aimed to contribute knowledge to help further understanding about a blended PBL group tutorial, with a specific focus on the tutor role. This involves the academics actively connecting their learning on the module with the potential for their own students and seeking out ways to integrate what they are learning into their practice. By gaining these new perspectives, their vision grows and extends to incorporating new facilitation strategies such as PBL tutoring through technological means. Participants ideally leave the module not only with more knowledgeable about the content matter, but with an expanded worldview, greater compassion, heightened self-awareness and with a commitment to produce change. Instead of serving as an impediment to a potentially transformative pedagogy such as PBL, learning technology can be a highly effective conduit for this style of academic development.

While it is not feasible to extrapolate the findings of the investigation beyond the present context, the analysis of the potential of the academic developer as tutor within blended PBL raises a number of issues worthy of comment. Concurring with Wheeler (2009) that the support needs of learners in online PBL remain crucial, this study argues that understanding and critically evaluating the tutor role and its potential for influencing the learning and practice of academic staff in their professional development is greater now more than ever. The tutor having the ability to improvise and to out-think the participants may become a hallmark in blended PBL of the future. 


\section{References}

Barrett, T. (2007) Students Talk About Problem-based Learning in PBL Tutorials: Illuminative Concepts. Unpublished PhD Thesis, Coventry University.

Barrows, H.S. (1987) The Tutorial Process (Springfield, Southern Illinois University).

Beaumont, C., Owens, T., \& Barrett-Baxendale, M. (2008) Blended problem-based learning for widening participation: A case study, HEA Academy Italics, 7(1).

Berge, Z.L. (1995) Facilitating Computer Conferencing: Recommendations from the Field, Educational Technology, 35, 22-30.

Blye F.W., Viscount, P.W., \& Mann, K. (2005) Tutor Training for PBL: Investigation, Review and Redesign to Develop Best Practices in Tutoring, International Conference on PBL 9-11 June 2005, Lahti, Finland.

Brescia, W.F. (2002) Using a Telementoring Taxonomy in a World Wide Web Instructional Environment: A Case Study, Indiana University.

Dolmans, D. (2002) Trends in Research on the Tutor in Problem-based Learning: Conclusions and Implications for Educational Practice and Research, Medical Teacher, 24(2). 
Driscoll, M. (2008) Reviewing Last Year's E-Learning Predictions. Available online at: http://www.elearnmag.org/subpage.cfm?section=articles\&article=73-1 $\quad$ Education and Technology in Perspective (accessed 15 September 2010).

Finkle, S.L. \& Torp, L.L. (1995) Introduction to PBL, (Illinois Math and Science Academy, The Center for Problem-Based Learning).

Fosnot, C.T. (1996) Constructivism: A Psychological Theory of Learning, in: C.T. Fosnot (Ed) Constructivism: Theory, Perspectives and Practice (New York, Teachers College Press) $(8-33)$.

Fox, R., \& Herrmann, A. (2000) Changing media, changing times: Coping with adopting new educational technologies. In T. Evans \& D. Nation (Eds.), Changing university teaching: Reflections on creating educational technologies (pp.73-84). London: Kogan Page.

Gunn, C. \& Harper, A. (2006) Using e-Learning to Transform Large Class Teaching in Making the Transition to E-Learning: Strategies and Issues, in: M. Bullen \& D. Janes (Eds) Making the transition to e-learning: Issues and strategies (Hershey PA, Idea Group Publishing).

Hmelo-Silver, C. E. \& Barrows, H. S. (2006) Goals and Strategies of a Problem-based Learning Facilitator, Interdisciplinary Journal of Problem-based Learning, 1(1), Article 4. Online available at: http://docs.lib.purdue.edu/ijpbl/vol1/iss1/4 (accessed 15 September 2010). 
Henri, F. (1992) Computer Conferencing and Content Analysis, in: A.R. Kaye (Ed)

Collaborative Learning through Computer Conferencing: The Najaden Papers (Berlin, Springer-Verlag) (117-136).

Jennings, D. (2006) PBLonline: A Framework for Collaborative e-Learning, in: M. SavinBaden, \& K. Wilkie (Eds) Problem-based Learning Online (Maidenhead, Open University Press) (105-123).

JISC (2009) Podcast: Supporting Academic Staff. Online available at:

http://www.jisc.ac.uk/Home/news/stories/2008/09/podcast57supportingacademicstaff.aspx (accessed15 September 2010).

Kolmos, A. (2002) Facilitating Change to a Problem-based Model, The International Journal for Academic Development, 7(1), 63-74.

Kolmos, A., Du, X., Dahms, M., \& Qvist, P. (2008) Staff Development for Change to Problem Based Learning, International Journal of Engineering Education, 24(4), 772-782.

Kulp, R. (1999) Effective Collaboration in Corporate Learning: Ten Best Practices for Curriculum Owners, Developers and Instructors, (IBM Learning Services, IBM Business Machines Corporation).

Levin, J. (1995, March) Organising Educational Network Interactions; Steps Towards a Theory of Network based Learning Environments, Paper presented at the Annual Meeting of the American Research Association, San Francisco. 
Lycke, K., Strømsø, H. \& Grøttum, P. (2002) PBL goes ICT: Problem-based Learning in Face-to-face and Distributed Groups in Medical Education at the University of Oslo, (University of Oslo, Institute for Educational Research). Report No.4.

MacLaren, I. (2005) New trends in academic staff development: reflective journals, teaching portfolios, accreditation and professional development, (Dublin, AISHE Readings).

Mayo, W.P., \& Donnelly, M.B. (1995) Characteristics of the ideal problem-based learning tutor in clinical medicine, Eval. Health Prof. 18, 124 -136.

Morris, G. (2005) From the Bottom up: a Pedagogy for Tutor Professional Development that Supports Problem-based Learning, International Conference on PBL 9-11 June 2005, Lahti, Finland.

Newman, M. (2004) Higher Education Academy Imaginative Curriculum Guide: Problem Based Learning. Online Available at:

http://www.heacademy.ac.uk/assets/York/documents/resources/resourcedatabase/id362_Imag inative_Curriculum_Guide_Problem_Based_Learning.rtf (accessed 10 January 2011).

Northedge, A. (2003) Enabling Participation in Academic Discourse, Teaching in Higher Education, 8(2), 169-180.

Osguthorpe, R.T., \& Graham, C. (2003) Blended learning environments, definitions and directions. Quarterly Review of Distance Education, 4(3), 227-233. 
Kamin, C.S., O’Sullivan, P., Deterding, R.R., Younger, M., \& Wade, T. (2006) A case study of teaching presence in virtual problem-based learning groups. Med Teach, 28(5), 425-428.

Park, S., Susarla, S., Cox, C., Da Silva, J., \& Howell, T. (2007) Do Tutor Expertise and Experience Influence Student Performance in a Problem-Based Curriculum? Journal of Dental Education, 71(6), 819-824.

Portimojärvi, T, \& Vuoskoski, P. (2006) A Promising Alliance of PBL, CMC and Leadership. Paper Presented at the $10^{\text {th }}$ International Conference on Experiential Learning, Hosted by the Brathay Academy in partnership with The International Consortium for Experiential Learning (ICEL), 10-14 July.

Robson, C. (1993) Real World Research: A Resource for Social Scientists and Practitioners. Oxford: Blackwell Publishing.

Rossiter, D. (2008) Innovative Problem-based learning approach using on and offline resources in 1st Year Chemical Engineering. Paper presented at Engineering Education Conference, 14 -16 July 2008, at Loughborough University, England.

Savin-Baden, M. (2003) Facilitating Problem Based Learning: Illuminating perspectives. Buckingham: Society for Research in Higher Education and Open University Press. 
Savin-Baden, M. (2006) The Challenge of Using Problem-based Learning Online, in: M. Savin-Baden \& K. Wilkie (Eds) Problem-based Learning Online (Maidenhead, Open University Press) (3-13).

Schön, D. (1991) The Reflective Practitioner, (London, Ashgate Publishing).

Shephard, K. (2004) The role of educational developers in the expansion of educational technology, International Journal for Academic Development, 9(1), 67-83

Smith, K.A., Sheppard, S.D., Johnson, D.W., \& Johnson, R.T. (2005) Pedagogies of engagement: Classroom-based Practices, Journal of Engineering Education, 1-15.

Taradi, S., Taradi, M., Radic, K., \& Pokrajac, N. (2005) Blending problem-based learning with Web technology positively impacts student learning outcomes in acid-base physiology, Advances in Physiology Education, 29, 35-39.

Teles, L. (2001) The Role of the Instructor in e-learning Collaborative Environments, TechKnowlogia, May/June, 46-50.

Vogel, M. (2009) The engagement of academics in professional development for e-learning. Presentation to the M25 Learning Technologists meet-up, 27 March 2009. Online available at: http://tinyurl.com/ckuqbr (accessed 20 September 2010). 
Wheeler, S. (2009) Learner support needs in online problem based learning, in: A Orellana, T L Hudgins \& M Simonson (Eds) The Perfect Online Course: Best Practices for Design and Teaching (Charlotte, NC, Information Age Publishers) (475-486). 